Check for updates

Cite this: RSC Adv., 2018, 8, 18327

Received 31st January 2018

Accepted 9th May 2018

DOI: $10.1039 / c 8 r a 00955 d$

rsc.li/rsc-advances

\section{A new red fluorophore with aggregation enhanced emission by an unexpected "One-step" protocol'}

\author{
Rui Wang, ${ }^{a}$ Meili Hou, ${ }^{a}$ Zhigang Xu, (D) ${ }^{a}$ Luxi Tan, (D) c Cheng Zhong*b \\ and Linna Zhu (DD *a
}

In this work, a triphenylamine-benzothiadiazole-based new fluorophore is obtained from a facile "onestep" protocol. A possible reduction mechanism is proposed, and an amine containing $\alpha-\mathrm{H}$ plays a key role in the reduction reaction. The resultant product $\mathrm{A} 1 \mathrm{H} 2$ exhibits bright red emission in solid state, with an absolute quantum yield of $44.5 \%$. Aggregation induced emission enhancement of $\mathrm{A} 1 \mathrm{H} 2$ is also observed with the increased water fraction in THF- $\mathrm{H}_{2} \mathrm{O}$ mixture. The nanoparticles of $\mathrm{A} 1 \mathrm{H} 2$ reveal good stability and biocompatibility, which are successfully applied in cellular cytoplasm imaging.

\section{Introduction}

Owing to their non-toxicity, good photostability as well as biodegradability, ${ }^{1}$ fluorescent organic nanoparticles (FONs) have revealed promising potential in fluorescence imaging, molecular probes and biosensors. ${ }^{2}$ However, many organic fluorophores suffer from aggregation-caused quenching (ACQ) when formed into nano-aggregates. Therefore, molecules exhibiting aggregation-induced emission (AIE) or aggregationinduced emission enhancement (AIEE) properties are highly desirable, and much effort has been made in developing such aggregation enhanced emission system during the past decades. $^{3}$ Among these AIEE systems, red luminescent molecules are of special interests for biosensing and bioimaging, because they could minimize photodamage to living cells, deepen the tissue penetration and surpass the biological background fluorescence interference. ${ }^{4}$ However, since the extended conjugation length (usually required for achieving red emission) or the non-ideal electron donor-acceptor combination easily leads to ACQ characteristics, ${ }^{5}$ development of red AIE/AIEE fluorophore remains a big challenge.

In this work, initially, we aim to synthesize a triphenylaminebenzothiadiazole-based red fluorophore A1 via Knoevenagel condensation reaction from the corresponding aldehyde and malononitrile. Generally, the aromatic aldehyde and

${ }^{a}$ Chongqing Key Laboratory for Advanced Materials and Technologies of Clean Energy, Faculty of Materials \& Energy, Southwest University, Chongqing 400715, P. R. China. E-mail:lnzhu@swu.edu.cn

${ }^{b}$ Department of Chemistry, Hubei Key Lab on Organic and Polymeric Optoelectronic Materials, Wuhan University, Wuhan 430072, P. R. China. E-mail: zhongcheng@ whu.edu.cn

'School of Chemistry and Chemical Engineering, Chongqing University, Chongqing 401331, P. R. China

$\dagger$ Electronic supplementary information (ESI) available. See DOI: $10.1039 / \mathrm{c} 8 \mathrm{ra00955d}$

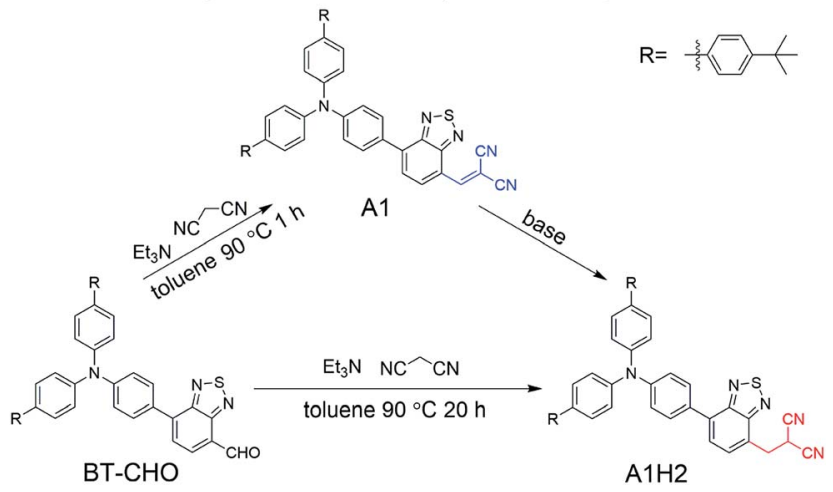

Scheme 1 Synthetic routes for $\mathrm{A} 1$ and $\mathrm{A} 1 \mathrm{H} 2$.

malononitrile undergo typical condensation to produce a dicyanoethyl group (as the structure of A1 in Scheme 1, marked in blue). Unexpectedly, in our case, its reduction product $\mathrm{A} 1 \mathrm{H} 2$ is directly obtained from such a reaction with no extra catalysts involved. A1 is later obtained within a shorter reaction duration. More interestingly, A1H2 shows strong red emission in the aggregation state with the maximum emission wavelength exceeding $640 \mathrm{~nm}$, whereas the more conjugated A1 has no obvious emission neither in solution nor in solid state. The resultant nanoparticles of A1H2 (NPs-A1H2) exhibit bright red emission with good stability and biocompatibility. Accordingly, the NPs-A1H2 are successfully applied in cellular cytoplasm imaging.

\section{Results and discussion}

The synthetic routes for $\mathrm{A} 1 \mathrm{H} 2$ are depicted in Scheme 1. The condensation product A1 was obtained in the initial stage of the reaction (less than $1 \mathrm{~h}$ ). Upon further increasing the reaction 
time (about $20 \mathrm{~h}$ ), A1 will completely convert into the reduced product $\mathrm{A} 1 \mathrm{H} 2$ spontaneously. To elucidate possible reaction pathways, three parallel experiments were carried out, using A1 as the main reactant, and triethylamine or malononitrile was added separately to $\mathrm{A} 1$ in toluene (Scheme $\mathrm{S} 2 \dagger$ ). The adduct formation process was monitored by High Performance Liquid Chromatography (HPLC). As shown in Fig. S1, $\dagger$ the pure A1 and $\mathrm{A} 1 \mathrm{H} 2$ have a retention time of $31.5 \mathrm{~min}$ and $19.7 \mathrm{~min}$, respectively. For the three parallel reaction systems, the condensation product A1 remained the same in systems without triethylamine, while the reduction product $\mathrm{A} 1 \mathrm{H} 2$ could only be detected in reaction system containing triethylamine (route 3, Scheme S2 $\dagger$ ). Different bases (piperidine, diethylamine and hexylamine) were also used during the conversion from A1 to $\mathrm{A} 1 \mathrm{H} 2$, respectively. The results were monitored using TLC plate $\left(\mathrm{CH}_{2} \mathrm{Cl}_{2}: \mathrm{PE}=1: 1\right)$ (Fig. $\left.\mathrm{S} 2 \dagger\right)$. It was found that $\mathrm{A} 1 \mathrm{H} 2$ was obtained after reacting for a long time (more than $12 \mathrm{~h}$ ) in the presence of piperidine or diethylamine. In striking contrast, A1H2 was obtained within several minutes when hexylamine was added to the solution of A1. This might be ascribed to the smaller steric hindrance of the primary amine compared with the secondary and tertiary amine, and the primary amine may participate in the conversion from $\mathrm{A} 1$ to $\mathrm{A} 1 \mathrm{H} 2$ directly, consequently, the reaction rate is significantly accelerated. To further study the possible mechanism, amantadine ( $3 \mathrm{mg}$ ) was used to react with $\mathrm{A} 1(10 \mathrm{mg})$ in toluene $(5 \mathrm{~mL})$ and stirred at $90{ }^{\circ} \mathrm{C}$ for $24 \mathrm{~h}$ under argon. Amantadine is an amine without $\alpha-\mathrm{H}$, which distinguishes it from other amines we used in this paper. The result was monitored by TLC (Fig. S3†). It is clear from the TLC result that no reducing product $(\mathrm{A} 1 \mathrm{H} 2)$ was detected. Based on these results, a possible mechanism is proposed, shown in Scheme 2. Firstly, dicyanovinyl group in A1 is attacked by amine, making the dicyanomethylene moiety negatively charged. And the hydrogen on amine is able to be attracted by the carbanion on dicyanovinyl moiety, followed by proton transfering to the benzothiadiazole group. Then, the $\mathrm{R}=\mathrm{NH}$ is released by eliminating the $\alpha-\mathrm{H}$ of amine, leaving negative charge on the dicyanovinyl moiety, which could be neutralized by getting a proton from the benzothiadiazole- $\mathrm{H}$. Therefore, when amantadine without $\alpha-\mathrm{H}$ is used, A1 cannot be reduced to $\mathrm{A} 1 \mathrm{H} 2$.

We speculate that the "one-step" protocol is able to be realized because there is a strong electron-deficient benzothiadiazole (BT unit) in A1, which makes the dicyanovinyl quite easily being reduced under basic condition (particularly primary amine). To verify this speculation, A2 incorporating a strong electron-donor 3,4-ethylenedioxythiophene (EDOT) to replace the BT segment was synthesized (Scheme S3†). However, the reducing product was not detected even after $24 \mathrm{~h}$ in the same condition of preparing $\mathrm{A} 1 \mathrm{H} 2$, further confirming the effect of the electron-deficient BT unit in the reduction process. To further illustrate this issue, the primary amine (hexylamine) is used in the reaction of A2. After reacting for $24 \mathrm{~h}$, the majority of A2 remains the same, and no reducing product of A2 appears, indicating $\mathrm{A} 2$ is difficult to be reduced compared to A1, as is shown in Fig. S4. $\dagger$ It has been widely reported that the reductive Knoevenagel condensation products can be obtained with the existence of expensive catalysts such as $\mathrm{Pd} / \mathrm{C},{ }^{6}$ rhodium $(\mathrm{Rh})$ catalysts $^{7}$ or in the presence of active hydrogen sources like Hantzsch ester, ${ }^{8} \mathrm{CaH}_{2}$ (ref. 9) and so forth. As far as we know, one-step Knoevenagel condensation/reduction without additional introduction of catalysts/active hydrogen source is rarely reported so far. According to the above results, such "one-step" protocol might easily be realized by incorporating electrondeficient unit adjacent to the dicyanovinyl moiety.

The absorption and emission spectra of A1H2 in THF are presented in Fig. 1a, with that of A1 for comparison. A1 exhibits two absorption bands at $335 \mathrm{~nm}$ and $553 \mathrm{~nm}$, respectively. The absorption band at $335 \mathrm{~nm}$ could be ascribed to the $\pi-\pi^{*}$ transition, while the band at $553 \mathrm{~nm}$ corresponds to the charge transfer (CT) from the triphenylamine framework to the electron-withdrawing benzothiadiazole and dicyanovinyl
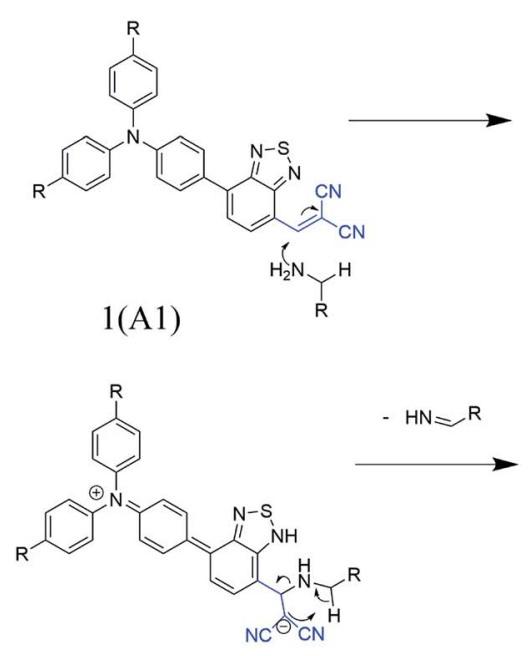

4
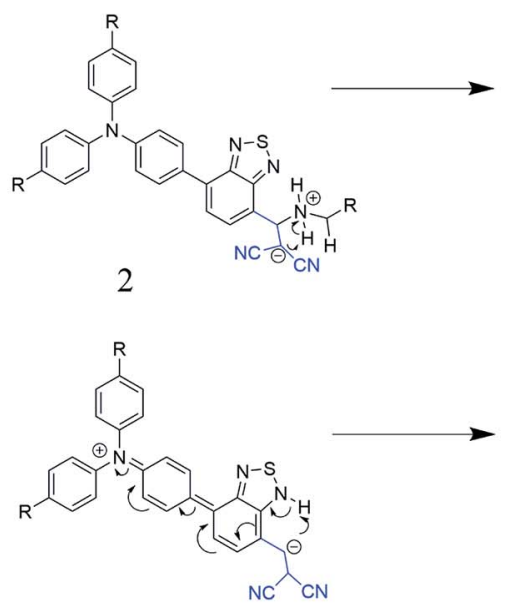

5
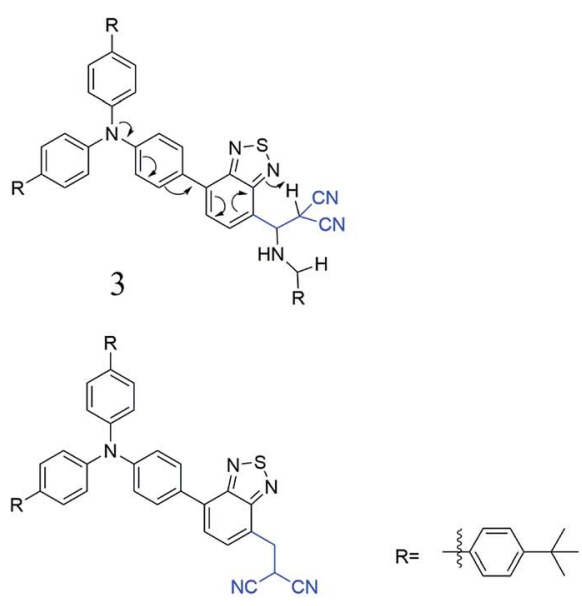

$6(\mathrm{~A} 1 \mathrm{H} 2)$

Scheme 2 A proposed mechanism for the conversion of A1 to $\mathrm{A} 1 \mathrm{H} 2$. 


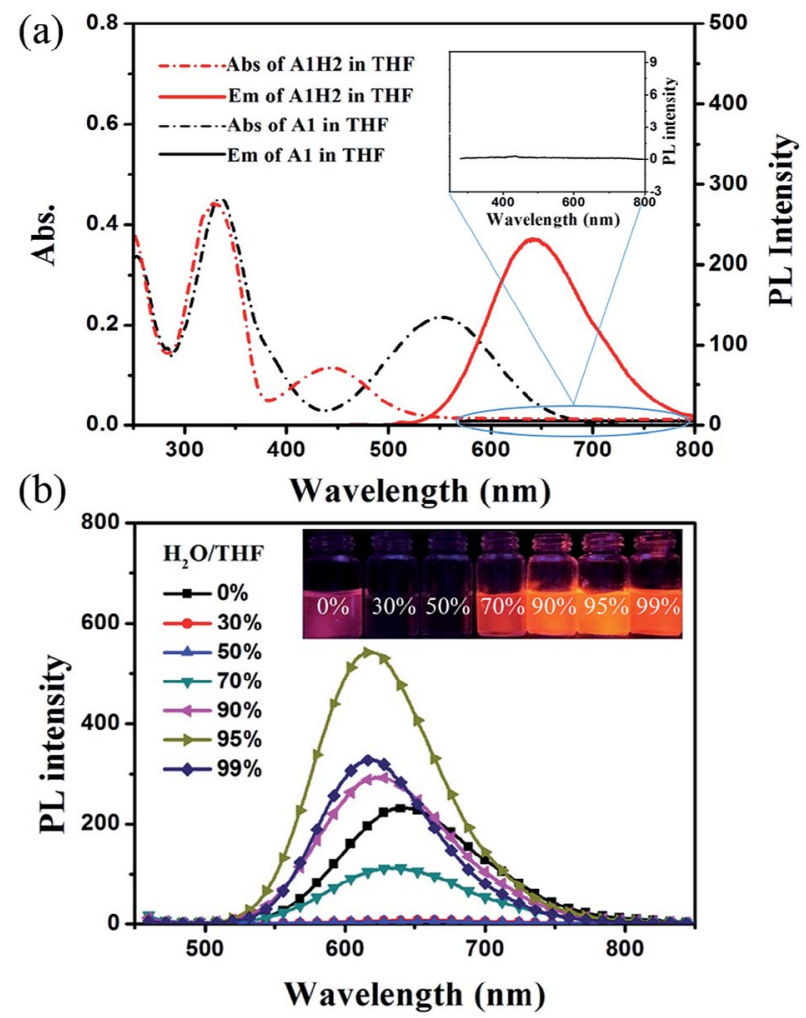

Fig. 1 (a) UV-vis absorption and PL emission spectra of A1 (black line) and $\mathrm{A} 1 \mathrm{H} 2$ (red line) in THF, (concentration: $10 \mu \mathrm{M}$ ). Inset: the enlarged emission spectra of $\mathrm{A} 1 \mathrm{in} \mathrm{THF}$. (b) $\mathrm{PL}$ spectra of $\mathrm{A} 1 \mathrm{H} 2$ in water/THF mixtures with different water fractions (concentration: $10 \mu \mathrm{M}$, excitation wavelength: $445 \mathrm{~nm}$ ). Inset: images of $\mathrm{A} 1 \mathrm{H} 2$ versus water fraction in THF-water mixtures.

moieties. Similar spectra are observed for $\mathrm{A} 1 \mathrm{H} 2$, except that the $\mathrm{CT}$ band in $\mathrm{A} 1 \mathrm{H} 2$ is blue-shifted compared to that in $\mathrm{A} 1$, because after hydrogenation of the double bond, the conjugation and electron-withdrawing ability of the acceptor is weakened in $\mathrm{A} 1 \mathrm{H} 2$. We also note that $\mathrm{A} 1$ is almost non-fluorescent in THF, probably caused by the strong intramolecular charge transfer and the strong diploe-diploe interaction. ${ }^{\mathbf{1 0}}$ In contrast, $\mathrm{A} 1 \mathrm{H} 2$ exhibits a weak purple fluorescence in THF ( $\left.\Phi_{\mathrm{F} .1}: 17.2 \%\right)$, and a strong bright red emission in the solid state $\left(\Phi_{\text {F.s }}: 44.5 \%\right)$ (Table 1). The bulky tert-butylbenzene moiety could effectively impede the unfavourable molecular aggregation in $\mathrm{A} 1 \mathrm{H} 2$, and the generated dicyanoethyl also contribute to bond rotation in $\mathrm{A} 1 \mathrm{H} 2$, and thus strong emission in the solid state is observed. ${ }^{5}$

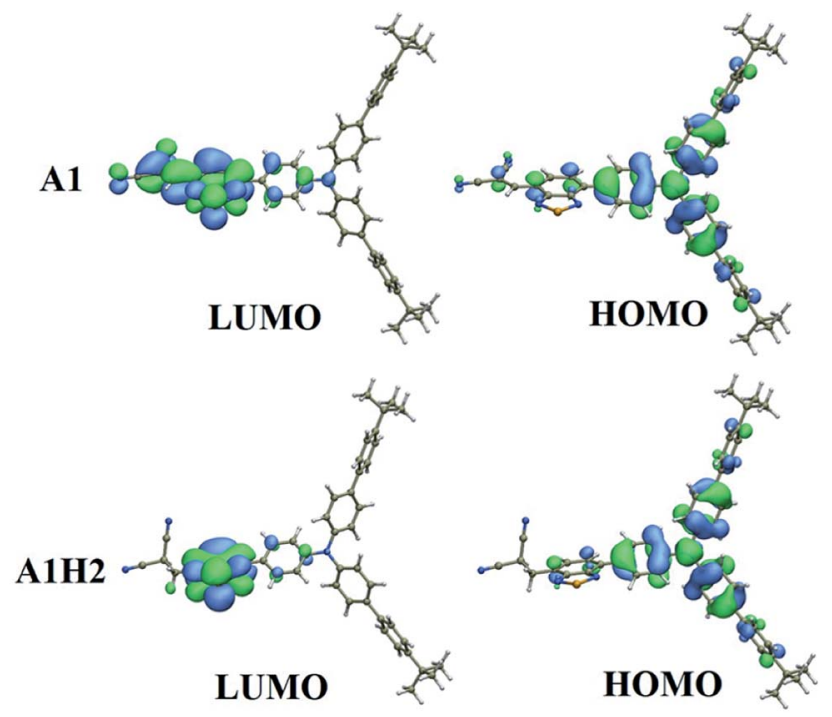

Fig. 2 Calculated molecular orbital amplitude plots of $\mathrm{HOMO}$ and LUMO levels for $\mathrm{A} 1$ and $\mathrm{A} 1 \mathrm{H} 2$.

In the meantime, it is noteworthy that the reductive product A1H2 exhibits large Stokes shift up to $190 \mathrm{~nm}$, which is beneficial for circumventing fluorescence quenching and eliminating background interference. ${ }^{\mathbf{1 1}}$

To better understand the properties of $\mathrm{A} 1 \mathrm{H} 2$, theoretical calculations were performed using the density functional theory (DFT) method at the B3LYP/6-31G (d)* level. ${ }^{12} \mathrm{~A} 1$ is also calculated for comparison. For both compounds, the HOMO levels are mainly localized over the TPA framework, and also partly distributed on the BT unit and the adjacent groups, while LUMO is primarily distributed on the acceptor moieties such as BT and malononitrile (Fig. 2). The HOMO-LUMO band gaps are calculated to be 2.15 and $2.77 \mathrm{eV}$ for $\mathrm{A} 1$ and $\mathrm{A} 1 \mathrm{H} 2$, respectively, which fit well with the experimental results, as calculated from the onset wavelength in the absorption spectrum (Table 1). ${ }^{13}$ Compared to A1, the hydrogenation of the dicyanovinyl group leads to weaker electron-withdrawing ability, and thus the energy bandgap of $\mathrm{A} 1 \mathrm{H} 2$ is larger than that of $\mathrm{A} 1$. On the other hand, the electron affinity of $\mathrm{A} 1$ and $\mathrm{A} 1 \mathrm{H} 2$ are calculated to be 3.25 and 2.39 respectively, suggesting that A1 has a stronger tendency to accept electrons in comparison with $\mathrm{A} 1 \mathrm{H} 2$.

Since $\mathrm{A} 1 \mathrm{H} 2$ is strongly emitting in the solid state, the emission properties of $\mathrm{A} 1 \mathrm{H} 2$ are also studied in $\mathrm{THF} /$ water mixtures,

Table 1 Spectral data of $\mathrm{A} 1 \mathrm{H} 2$ and $\mathrm{A} 1$

\begin{tabular}{|c|c|c|c|c|c|c|c|}
\hline Compound & $\lambda_{\mathrm{abs}}{ }^{a} / \mathrm{nm}$ & $E_{\mathrm{g}}^{\mathrm{opt} b} / \mathrm{eV}$ & $E_{\mathrm{g}}^{\mathrm{calcc}} / \mathrm{eV}$ & Electron affinity & \multicolumn{3}{|l|}{$\lambda_{\mathrm{em}}{ }^{d} / \mathrm{nm}$} \\
\hline $\mathrm{A} 1$ & 553 & 1.90 & 2.15 & 3.25 & n.d. & n.d. & n.d \\
\hline
\end{tabular}

${ }^{a}$ Absorption maximum $\left(\lambda_{\text {abs }}\right)$ in THF. ${ }^{b}$ The optical band gap $\left(E_{\mathrm{g}}^{\mathrm{opt}}\right)$ calculated from the onset wavelength in the absorption spectrum. ${ }^{c}$ HOMOLUMO band gap $\left(E_{\mathrm{g}}^{\text {calc }}\right)$ calculated from theoretical DFT calculations. ${ }^{d}$ Emission maximum $\left(\lambda_{\text {em }}\right)$ derived from THF solution (soln, $\left.10 \mu \mathrm{M}\right)$, THF/ water mixture (aggr, $5: 95 \mathrm{v} / \mathrm{v}$ for $\mathrm{A} 1 \mathrm{H} 2 ; 10 \mu \mathrm{M}$ ) and in the solid state, respectively. ${ }^{e} \Phi_{\mathrm{F}}$ is the fluorescence quantum efficiency measured by a calibrated integrating sphere. 
as shown in Fig. 1b. In THF, A1H2 exhibits light purple emission with the maximum band at $643 \mathrm{~nm}$. Upon gradual addition of water into THF $\left(f_{\mathrm{w}} \leq 60 \%, f_{\mathrm{w}}\right.$ stands for water fraction in THFwater mixtures), the emission of $\mathrm{A} 1 \mathrm{H} 2$ is quenched dramatically. Whereas, fluorescence intensity increases with continuing increase in $f_{\mathrm{w}}$, indicating aggregation induced emission enhancement feature of $\mathrm{A} 1 \mathrm{H} 2 .^{3 \boldsymbol{e}, \mathbf{1 4}}$ The emission intensity reaches the maximum when water fraction is $95 \%$. It is noteworthy that the absolute fluorescence quantum yields $\left(\Phi_{\mathrm{F}}\right)$ of $\mathrm{A} 1 \mathrm{H} 2$ in THF-water $\left(f_{\mathrm{w}}=95 \%\right)$ is as high as $35.8 \%$, which is a relatively high value among previously reported red-emissive AIE molecules. $^{2 \boldsymbol{b}, \mathbf{1 5}}$ Additionally, the absorption spectra is conducted at different water/THF concentrations, as shown in Fig. S6. $\dagger$ It is clear that the absorption maximum exhibits a slight blue shift with water fraction increasing to $50 \%$. This blue shift originates from the formation of $\mathrm{H}$-aggregates, which leads to emission quenching. When more water is added, the intramolecular rotations are further restricted contributing to the enhanced light emission. ${ }^{16}$ In the meantime, molecules get more distorted in the aggregation state. Thus, the weakened intermolecular interaction with the increase of water fraction should be responsible for the blue shift of emission wavelength in the nanoparticles. Given the merits of red emission and high fluorescence efficiency, $\mathrm{A} 1 \mathrm{H} 2$ has great potential to be a candidate for bio-imaging applications.

A1H2-NPs are prepared using a reprecipitation method. ${ }^{1 b}$ Fig. 3a shows the absorption and emission spectral of $\mathrm{A} 1 \mathrm{H} 2-$ NPs dispersed in water. The absorption peak of the $\mathrm{A} 1 \mathrm{H} 2$ nanoparticles exhibits a slight bathochromic shift of $\sim 15 \mathrm{~nm}$ relative to that measured in THF, owing to the formation of $J$ aggregates. ${ }^{17}$ While the emission maximum of A1H2-NPs appears at $616 \mathrm{~nm}$, corresponding to a blue-shift of $27 \mathrm{~nm}$ compared with that measured in THF. The blue-shift in emission maximum is probably ascribed to the more twisted
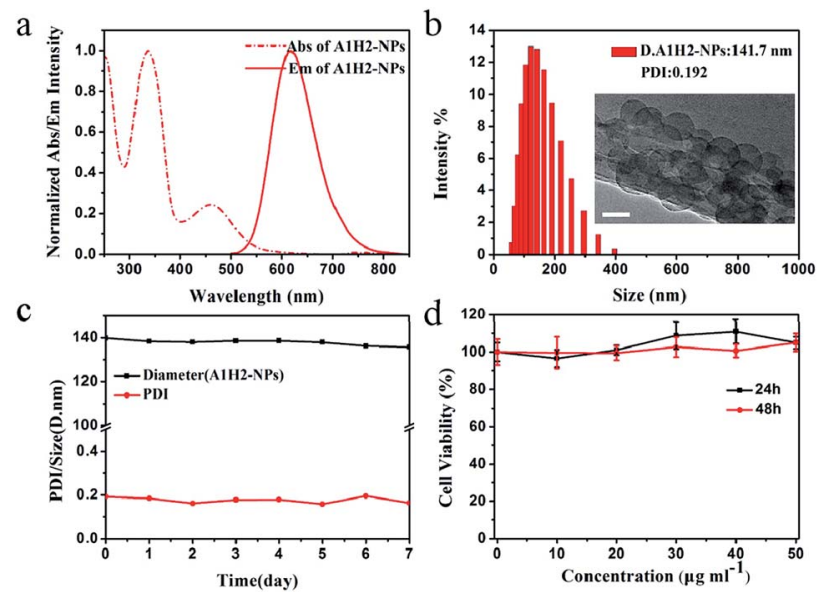

Fig. 3 (a) Normalized UV-vis absorption and PL spectra of A1H2-NPs dispersed in water. (b) The size distribution, diameter and PDI value of the as-prepared $\mathrm{A} 1 \mathrm{H} 2-\mathrm{NPs}$ measured by dynamic light scattering (DLS). Inset: TEM image of A1H2-NPs morphology (scale bar $=50 \mathrm{~nm}$ ). (c) Size-stabilities including diameters and PDI values of the A1H2-NPs. (d) Cell viability of HeLa cells after incubation with 0, 10, 20, 30, 40 and $50 \mu \mathrm{g} \mathrm{mL}^{-1} \mathrm{~A} 1 \mathrm{H} 2-\mathrm{NPs}$ for $24 \mathrm{~h}, 48 \mathrm{~h}$, respectively. conformation of $\mathrm{A} 1 \mathrm{H} 2$ molecules in the nano-aggregates. ${ }^{3 g, 18}$ Dynamic light scattering (DLS) measurements reveal that the nanoparticles formed have a volume averaged hydrodynamic diameter of $141.7 \mathrm{~nm}$ with a PDI of 0.192 (Fig. 3b). Zetapotential of A1H2-NPs in aqueous solution is measured to be $-35.0 \mathrm{mV}$. The high negative surface of the NPs demonstrates the formation of hydrogen bonds between $\mathrm{H}_{2} \mathrm{O}$ and the $\mathrm{N}$ atoms in benzothiadiazole and malononitrile moieties. ${ }^{19}$ Definitely, the negative surface will improve the dispersion stability of the nanoparticles due to the electrostatic repulsion effect. The morphology of A1H2-NPs is further investigated using TEM, as shown in Fig. 3b. Spherical nanoparticles with diameters of around $70 \mathrm{~nm}$ are observed.

The size and PDI values of the as-prepared NPs are monitored for 7 days in a row, as shown in Fig. 3c. It is observed that the size of NPs remains around $140 \mathrm{~nm}$ from DLS results, and PDI is still below 0.20 . Therefore, the as-prepared NPs could be stably dispersed in water and maintained for a long period. On the other hand, the stability of A1H2-NPs in buffer solutions at different $\mathrm{pH}$ values is also examined (Fig. S7†). Fluorescence intensity of the NPs does not show significant changes with $\mathrm{pH}$ ranging from 2 to 9, demonstrating that the A1H2-NPs have excellent physiological performance over a wide range of $\mathrm{pH}$ values. These results make $\mathrm{A} 1 \mathrm{H} 2-\mathrm{NPs}$ favourable for bioimaging applications. Fig. 3d shows the cell viabilities after incubation with the A1H2-NPs suspension at different concentrations ranging from 10 to $50 \mu \mathrm{g} \mathrm{mL}^{-1}$ for 24 and $48 \mathrm{~h}$, respectively. Little change in cell viability is detected in these conditions, suggesting that the A1H2-NPs have almost no cytotoxicity toward HeLa cells even at a high concentration of 50 $\mu \mathrm{g} \mathrm{mL}{ }^{-1}$ for $48 \mathrm{~h}$.

Fluorescence imaging is performed on HeLa cells to verify the cellular uptake and localization of the A1H2-NPs. DAPI was

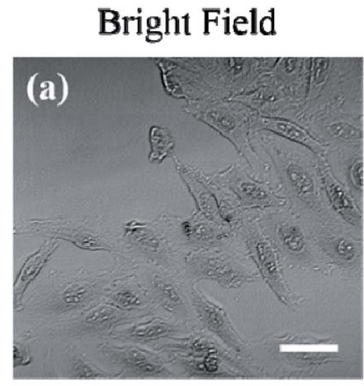

AlH2-NPs Channel

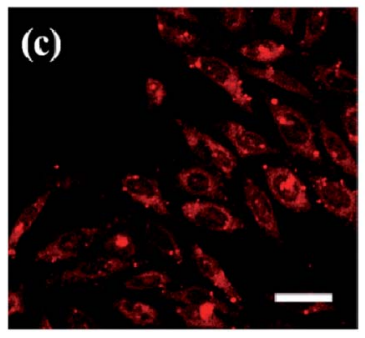

DAPI Channel

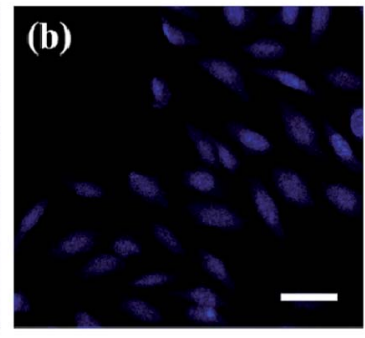

Merge

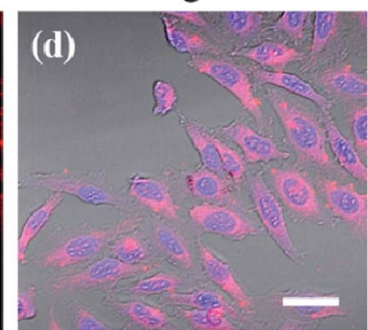

Fig. 4 Cellular imaging of HeLa cells stained with both A1H2-NPs and DAPI: (a) bright-field image, (b) blue fluorescence channel (DAPI channel), (c) red fluorescence channel (A1H2-NPs channel), (d) merged image from (a)-(c) (scale bar $=50 \mu \mathrm{m}$ ). 
chosen to stain the nuclei before cellular imaging. When DAPI molecules and A1H2-NPs were used in cell staining, blue fluorescence from DAPI channel could be observed in the cell nucleus, and the red fluorescence is detected in the cytoplasm of the HeLa cells using A1H2-NPs (Fig. 4b and c). The merged image in Fig. 4d suggests the excellent overlapping. These results indicate that the as-prepared $\mathrm{A} 1 \mathrm{H} 2$-NPs are biocompatible with HeLa cells and can function as an effective visualizer for cellular cytoplasm imaging.

\section{Conclusions}

In summary, a new red fluorophore $\mathrm{A} 1 \mathrm{H} 2$ is synthesized through an unexpected "one-step" protocol. Strong electronwithdrawing group adjacent to dicyanovinyl is demonstrated to be a prerequisite structural requirements. Amine with $\alpha-\mathrm{H}$ is also an important factor for the reduction to take place. $\mathrm{A} 1 \mathrm{H} 2$ exhibits bright red emission in solid state, with a high fluorescence quantum yield. A1H2-NPs are prepared, and are successfully applied for cellular cytoplasm imaging. The discovery in this work may provide new insight into realizing red emission fluorophore with aggregation enhanced emission feature.

\section{Experimental section}

\section{General methods}

The materials used in experiments were purchased from J\&K Chemical or HWRK Chem Co. and were used without further purification. Tetrahydrofuran (THF) and toluene were distilled over Na-K alloy under argon ambience prior to use. Other solvents were provided by local agents. The ${ }^{1} \mathrm{H}$ NMR and ${ }^{13} \mathrm{C}$ NMR spectra were recorded on a BRUKER AVANCE III $600 \mathrm{MHz}$ NMR Instrument (in $\mathrm{CDCl}_{3}$ ). HRMS was performed on a Thermo Scientific Q Exactive instrument. High Performance Liquid Chromatography (HPLC) was performed on a QS-C18 column with mobile phase of acetonitrile at a flow rate of 1.0 $\mathrm{mL} \min ^{-1}$. UV-vis absorption spectra were measured on a LAMBDA 950 UV/Vis/NIR Spectrophotometer. FL spectra were studied on Hitachi F-7000 spectrophotometer. The size distributions and Zeta-potential of the NPs in aqueous solution were measured by the dynamic light scattering technique with a Malvern Zetasizer Nano ZS90. The morphology of the NPs was observed using a JSM-2100. Fluorescence quantum yields were measured using an absolute PL quantum yield spectrometer C11347 Hamamatsu.

\section{General procedure for the preparation of $\mathrm{A} 1$}

To a solution of A1-3 (300 mg, $0.45 \mathrm{mmol}$ ) and malononitrile (90 mg, $1.36 \mathrm{mmol}$ ) in $15 \mathrm{~mL}$ of toluene was added $0.20 \mathrm{~mL}$ of triethylamine. After being stirred at $90{ }^{\circ} \mathrm{C}$ for $1 \mathrm{~h}$ under argon atmosphere, the reaction mixture was poured into water and then extracted with $\mathrm{CH}_{2} \mathrm{Cl}_{2}$. The organic extract was dried over anhydrous $\mathrm{Na}_{2} \mathrm{SO}_{4}$ and was further purified by column chromatography using a dichloromethane/hexanes (1:1) mixture as the eluent. Compound A1 was isolated as a dark powder in $68 \%$ yield. ${ }^{1} \mathrm{H}$ NMR $\left(600 \mathrm{MHz}, \mathrm{CDCl}_{3}\right) \delta 8.83(\mathrm{~s}, 1 \mathrm{H}), 8.79(\mathrm{~d}, J=$ $7.8 \mathrm{~Hz}, 1 \mathrm{H}), 8.02(\mathrm{~d}, J=9.0 \mathrm{~Hz}, 2 \mathrm{H}), 7.88(\mathrm{~d}, J=7.8 \mathrm{~Hz}, 1 \mathrm{H}), 7.57$ $(\mathrm{dd}, J=12.5,8.5 \mathrm{~Hz}, 8 \mathrm{H}), 7.48(\mathrm{~d}, J=9.0 \mathrm{~Hz}, 4 \mathrm{H}), 7.30(\mathrm{~d}, J=$ $9.0 \mathrm{~Hz}, 6 \mathrm{H}), 1.37$ (s, 18H). ${ }^{13} \mathrm{C} \mathrm{NMR}\left(150 \mathrm{MHz}, \mathrm{CDCl}_{3}\right) \delta 153.63$, 151.74, 149.24, 148.67, 144.69, 138.97, 136.48, 135.96, 129.84, $129.74,127.70,127.00,125.44,124.92$, 124.76, 124.67, 120.91, 120.63, 112.91, 112.13, 81.33, 33.53, 30.36. MALDI-TOF-MS: calcd for $\mathrm{C}_{48} \mathrm{H}_{41} \mathrm{~N}_{5} \mathrm{~S}:$ 719.3077, found 719.3079.

\section{Synthesis of compound A1H2}

$\mathrm{A} 1 \mathrm{H} 2$ was synthesized following the same method as that of A1. Except it was reacted for another $19 \mathrm{~h}$. Reddish powder in $37 \%$ yield. ${ }^{1} \mathrm{H}$ NMR $\left(600 \mathrm{MHz}, \mathrm{CDCl}_{3}\right) \delta 7.87(\mathrm{~d}, J=8.4 \mathrm{~Hz}, 2 \mathrm{H}), 7.69$ $(\mathrm{d}, J=7.2 \mathrm{~Hz}, 1 \mathrm{H}), 7.66(\mathrm{~d}, J=7.2 \mathrm{~Hz}, 1 \mathrm{H}), 7.54(\mathrm{~d}, J=8.4 \mathrm{~Hz}$, $8 \mathrm{H}), 7.46(\mathrm{~d}, J=7.8 \mathrm{~Hz}, 4 \mathrm{H}), 7.29(\mathrm{~d}, J=8.4 \mathrm{~Hz}, 2 \mathrm{H}), 7.27(\mathrm{~s}, 2 \mathrm{H})$, $7.25(\mathrm{~s}, 2 \mathrm{H}), 4.76(\mathrm{t}, J=7.8 \mathrm{~Hz}, 1 \mathrm{H}), 3.82(\mathrm{~d}, J=7.8 \mathrm{~Hz}, 2 \mathrm{H}), 1.37$ (s, 18H). ${ }^{13} \mathrm{C}$ NMR (150 MHz, $\left.\mathrm{CDCl}_{3}\right) \delta 153.32,152.71,149.04$, $147.37,146.23$, 136.64, 136.21, 133.93, 130.04, 129.14, 129.08, 126.86, 125.64, 125.39, 124.72, 124.09, 122.72, 121.98, 111.31, 33.51, 33.43, 30.37, 21.66. HRMS (APCI): calcd for $\mathrm{C}_{48} \mathrm{H}_{44} \mathrm{~N}_{5} \mathrm{~S}[\mathrm{M}$ $+\mathrm{H}]^{+}:$722.3319, found 722.3331 .

\section{Preparation of the A1H2-NPs}

A1H2-NPs were prepared using a reported reprecipitation method. Two hundred microliters of the A1H2/THF solution (1 $\mathrm{mg} \mathrm{mL}^{-1}$ ) was quickly added to $5 \mathrm{~mL}$ of deionized water under vigorous stirring for $10 \mathrm{~min}$ at room temperature. And then, the A1H2-NPs suspension was sonicated for another 30 min under room temperature. The residual THF was removed by stirring slowly for two days.

\section{Cytotoxicity by prestoblue assay}

The cytotoxicity of The A1H2-Nps against HeLa cells was assessed by Prestoblue Cell Viability reagent (invitrogen, USA). The HeLa cells were plated in 96-well plates. After growing overnight, cells were treated with $200 \mu \mathrm{L}$ A1H2-NPs at various concentrations $\left(10,20,30,40\right.$ and $\left.50 \mu \mathrm{g} \mathrm{mL}^{-1}\right)$ for 24 and $48 \mathrm{~h}$ at $37{ }^{\circ} \mathrm{C}$ in the presence of $5 \% \mathrm{CO}_{2}$, and then the original medium in each well was removed. Subsequently, $100 \mu \mathrm{L}$ of the PrestoBlue ${ }^{\circledR}$ reagent was diluted to a final concentration of $10 \%$ and was added to the wells, and the cells were incubated for $1 \mathrm{~h}$. PrestBlue assay was employed to measure the cell viability of samples. Resazurin, a non-fluorescent blue compound in PrestoBlue ${ }^{\circledR}$ reagent with a maximum absorption at $600 \mathrm{~nm}$ can be reduced by living cells to resorufin with a maximum absorption at $570 \mathrm{~nm}$, which shows a red emission. Cell viability can be calculated relative to the control cells without treatment, by measuring the absorbance at 570 and $600 \mathrm{~nm}$, respectively.

\section{Live cell imaging experiments}

HeLa cells were cultured with DMEM containing 10\% FBS in $37{ }^{\circ} \mathrm{C}$ and $5 \% \mathrm{CO}_{2}$ with a humidified atmosphere. Then, the cells were seeded on six well plates and allowed to adhere at $37{ }^{\circ} \mathrm{C}$ and $5 \% \mathrm{CO}_{2}$ for overnight. The A1H2-NPs in PBS buffer as control were added to each plate (final concentration $[\mathrm{A} 1 \mathrm{H} 2-$ 
$\left.\mathrm{NPs}]=20 \mu \mathrm{g} \mathrm{mL} \mathrm{m}^{-1}\right)$. The medium was removed after incubation at $37{ }^{\circ} \mathrm{C}$ for $4 \mathrm{~h}$, and the plates were washed several times with PBS buffer. Before the treated cells were fixed, the cell nuclei were stained by $4^{\prime}, 6$-diamidino-2-phenylindole (DAPI) for $20 \mathrm{~min}$. Finally, fluorescent images were observed with Zeiss LSM 510 confocal laser scanning microscope.

\section{Conflicts of interest}

There are no conflicts to declare.

\section{Acknowledgements}

The authors thank the National Natural Science Foundation of China (No.51203046 and No. 51203121), the "Fundamental Research Funds for the Central Universities" (XDJK2017D001) and Chongqing Science and Technology Commission (cstc2013jcyjA50001 and cstc2016jcyjA0078) for financial support.

\section{Notes and references}

1 (a) J. Wang, X. Xu, L. Shi and L. Li, ACS Appl. Mater. Interfaces, 2013, 5, 3392-3400; (b) J. Zhang, R. Chen, Z. Zhu, C. Adachi, X. Zhang and C.-S. Lee, ACS Appl. Mater. Interfaces, 2015, 7, 26266-26274; (c) D. T. Jayaram, S. Ramos-Romero, B. H. Shankar, C. Garrido, N. Rubio, L. Sanchez-Cid, S. B. Gómez, J. Blanco and D. Ramaiah, ACS Chem. Biol., 2016, 11, 104-112; (d) W. Qin, D. Ding, J. Liu, W. Z. Yuan, Y. $\mathrm{Hu}$, B. Liu and B. Z. Tang, Adv. Funct. Mater., 2012, 22, 771-779; (e) E. Genin, Z. Gao, J. A. Varela, J. Daniel, T. Bsaibess, I. Gosse, L. Groc, L. Cognet and M. BlanchardDesce, Adv. Mater., 2014, 26, 2258-2261.

2 (a) W. Zhang, B. Tang, X. Liu, Y. Liu, K. Xu, J. Ma, L. Tong and G. Yang, Analyst, 2009, 134, 367-371; (b) A. Nicol, W. Qin, R. T. K. Kwok, J. M. Burkhartsmeyer, Z. Zhu, H. Su, W. Luo, J. W. Y. Lam, J. Qian, K. S. Wong and B. Z. Tang, Chem. Sci., 2017, 8, 4634-4643; (c) J. Zhou, V. K. Outlaw, C. A. Townsend and A. E. Bragg, Chem.-Eur. J., 2016, 22, 15212-15215; (d) K. Tateno, R. Ogawa, R. Sakamoto, M. Tsuchiya, T. Otani and T. Saito, Org. Lett., 2014, 16, 3212-3215; (e) V. K. Outlaw, J. Zhou, A. E. Bragg and C. A. Townsend, RSC Adv., 2016, 6, 61249-61253.

3 (a) W. Qin, K. Li, G. Feng, M. Li, Z. Yang, B. Liu and B. Z. Tang, Adv. Funct. Mater., 2014, 24, 635-643; (b) L. Yao, S. Zhang, R. Wang, W. Li, F. Shen, B. Yang and Y. Ma, Angew. Chem., Int. Ed., 2014, 53, 2119-2123; (c) H. Lu, Y. Zheng, X. Zhao, L. Wang, S. Ma, X. Han, B. Xu, W. Tian and H. Gao, Angew. Chem., Int. Ed., 2016, 55, 155-159; (d) Y. Hong, J. W. Y. Lam and B. Z. Tang, Chem. Commun., 2009, 4332-4353; (e) J. Luo, Z. Xie, J. W. Y. Lam, L. Cheng, H. Chen, C. Qiu, H. S. Kwok, X. Zhan, Y. Liu, D. Zhu and B. Z. Tang, Chem. Commun., 2001, 1740-1741; (f) J. Mei, N. L. C. Leung, R. T. K. Kwok, J. W. Y. Lam and B. Z. Tang, Chem. Rev., 2015, 115, 11718-11940; (g) Y. Liu, Y. Zhang, X. Wu, Q. Lan, C. Chen, S. Liu, Z. Chi, L. Jiang, X. Chen and J. Xu, J. Mater. Chem. C, 2014, 2, 1068-1075; (h) L. Yan, Y. Zhang, B. Xu and W. Tian, Nanoscale, 2016, 8, 2471-2487. 4 (a) H.-W. Liu, X.-B. Zhang, J. Zhang, Q.-Q. Wang, X.-X. Hu, P. Wang and W. Tan, Anal. Chem., 2015, 87, 8896-8903; (b) W. Zhu, X. Huang, Z. Guo, X. Wu, H. Yu and H. Tian, Chem. Commun., 2012, 48, 1784-1786; (c) M. Kaur and D. H. Choi, Chem. Soc. Rev., 2015, 44, 58-77; (d) L. Yuan, W. Lin, K. Zheng, L. He and W. Huang, Chem. Soc. Rev., 2013, 42, 622-661.

5 (a) C.-T. Chen, Chem. Mater., 2004, 16, 4389-4400; (b) Z. Wang, L. Yan, L. Zhang, Y. Chen, H. Li, J. Zhang, Y. Zhang, X. Li, B. Xu, X. Fu, Z. Sun and W. Tian, Polym. Chem., 2014, 5, 7013-7020.

6 K. Motokura, N. Fujita, K. Mori, T. Mizugaki, K. Ebitani and K. Kaneda, Tetrahedron Lett., 2005, 46, 5507-5510.

7 S. E. Denmark, M. Y. S. Ibrahim and A. Ambrosi, ACS Catal., 2017, 7, 613-630.

8 D. B. Ramachary, M. Kishor and K. Ramakumar, Tetrahedron Lett., 2006, 47, 651-656.

9 C. Guyon, M. C. Duclos, M. Sutter, E. Metay and M. Lemaire, Org. Biomol. Chem., 2015, 13, 7067-7075.

10 X. Y. Shen, Y. J. Wang, E. Zhao, W. Z. Yuan, Y. Liu, P. Lu, A. Qin, Y. Ma, J. Z. Sun and B. Z. Tang, J. Phys. Chem. C, 2013, 117, 7334-7347.

11 (a) Y. J. Wang, Y. Shi, Z. Wang, Z. Zhu, X. Zhao, H. Nie, J. Qian, A. Qin, J. Z. Sun and B. Z. Tang, Chem.-Eur. J., 2016, 22, 9784-9791; (b) H. Yuan, L. Wang, S. Li, H. Liang, C. Lu, Y. Wang and C.-H. Zhao, J. Phys. Chem. B, 2016, 4, 5515-5518; (c) Y. Zhang, J.-H. Wang, W. Zheng, T. Chen, Q.-X. Tong and D. Li, J. Mater. Chem. B, 2014, 2, 4159-4166.

12 M. J. Frisch, G. W. Trucks, H. B. Schlegel, G. E. Scuseria, M. A. Robb and J. R. Cheeseman, et al., Gaussian 09, Revision A.02, Gaussian, Inc., Wallingford CT, 2009.

13 A. Operamolla, S. Colella, R. Musio, A. Loiudice, O. Hassan Omar, G. Melcarne, M. Mazzeo, G. Gigli, G. M. Farinola and F. Babudri, Sol. Energy Mater. Sol. Cells, 2011, 95, 3490-3503.

14 (a) L. Zhu, R. Wang, L. Tan, X. Liang, C. Zhong and F. Wu, Chem.-Asian J., 2016, 11, 2932-2937; (b) W. Huang, H. Wang, L. Sun, B. Li, J. Su and H. Tian, J. Mater. Chem. C, 2014, 2, 6843-6849.

15 (a) Q. Zhao and J. Z. Sun, J. Mater. Chem. C, 2016, 4, 1058810609; (b) D. Yang, S. Zhang, Y. Hu, J. Chen, B. Bao, L. Yuwen, L. Weng, Y. Cheng and L. Wang, RSC Adv., 2016, 6, 114580-114586.

16 (a) A. Punzi, E. Maiorano, F. Nicoletta, D. Blasi, A. Ardizzone, N. Ventosa, I. Ratera, J. Veciana and M. Farinola Gianluca, Eur. J. Org. Chem., 2016, 15, 2617-2627; (b) D. D. Prabhu, A. P. Sivadas and S. Das, J. Mater. Chem. C, 2014, 2, 70397046; (c) S. Varghese, N. S. S. Kumar, A. Krishna, D. S. S. Rao, S. K. Prasad and S. Das, Adv. Funct. Mater., 2009, 19, 2064-2073.

17 A. Diac, D. Demeter, M. Allain, I. Grosu and J. Roncali, Chem.-Eur. J., 2015, 21, 1598-1608.

18 N. Zhao, M. Li, Y. Yan, J. W. Y. Lam, Y. L. Zhang, Y. S. Zhao, K. S. Wong and B. Z. Tang, J. Mater. Chem. C, 2013, 1, 46404646. 
19 (a) J. Zhang, W. Chen, S. Kalytchuk, K. F. Li, R. Chen, C. Adachi, Z. Chen, A. L. Rogach, G. Zhu, P. K. Yu, W. Zhang, K. W. Cheah, X. Zhang and C. S. Lee, ACS Appl.
Mater. Interfaces, 2016, 8, 11355-11365; (b) C. Mastrodonato, P. Pagano, J. Daniel, M. Vaultier and M. Blanchard-Desce, Molecules, 2016, 21, 1227-1251. 